\title{
Research on Core Technology of Oil Automation Drilling
}

\author{
Rongkang Zhu ${ }^{1}$ \\ ${ }^{1}$ Xi'an Petroleum University, Xi'an, Shaanxi, 710065
}

\section{KEYWORDS: Core Technology; Oil Automation Drilling}

\begin{abstract}
Oil is one of the main ways to solve the energy shortage problem, in order to ease China's energy shortage situation, we must fully exploit the natural resources. China has abundant oil resources underground, underground oil resources exploitation, exploration drilling is the most effective way, it is possible to simplify the production process to improve oil production. And before the traditional mode of production compared to oil, China's oil drilling process a great breakthrough in the use of technology, through the use of automation technology, the oil companies have a reliable guarantee.
\end{abstract}

\section{Introduction}

In recent years, the rapid development of China's science and technology, science and technology has been introduced to the field of oil exploration. Found down hole information technology, guidance and communication systems in underground mining process oil has been widely popularized. In this current situation of social development, oil drilling technology by the mechanization and automation of information together constitute the oil companies and units from all the attention, in practice, gradually formed a theoretical system and workflow system. With the rise of science and technology integrated use of IT industry in the oil drilling and oil drilling to the development of technology has brought a broad space.

The rapid development of China's market economy makes the demand for a variety of social energy growing, oil is a common resource for industrial production and daily life, to create a scientific model to improve oil drilling crude oil production is very helpful. To get rid of the shortcomings of traditional drilling technology exists in the development of mining companies plan to introduce a number of advanced automation technology. This not only reduces the production cost of the investment, but also significantly improves the yield of the crude product.

\section{The Shortcomings of Conventional Oil Drilling}

Our country is oil-rich country, has abundant oil resources, China's annual oil extraction has been in the forefront of the world. With the development and population surge in the number of China's economy, the demand for energy resources is growing. Traditional oil drilling is the main way of crude oil, but this way of exploitation at the technical level, the mining technology is relatively backward, the production output of oil is relatively low. Traditional oil pattern compared with the use of modern technology, oil drilling, deficiencies exist in the following areas:

Science and technology are primary productive forces, the use of advanced drilling technology, not only the efficiency of oil exploration oil companies has been greatly improved, but also greatly reduces the difficulty of the operation of the production staff. China's traditional oil extraction 
technology is relatively backward, oil drilling technology is not mature, crude oil exploitation more difficult, severely restricted the rapid development of China's crude oil extraction industry.

One of the important factors in the slow development of China's petroleum industry is the result of the relatively high cost of inputs. For oil exploration, the initial investment is relatively large, not been able to recover the costs in the short term, resulting in the early development of the oil industry is very slow. Oil well maintenance, but also require a large investment. The economic benefits and ultimately enterprises often expected difference is relatively large and these factors lead to early development of China's oil industry is still lagging behind the stage.

In conventional oil drilling, no advanced surveying techniques to crude oil production has brought a lot of trouble, pre-designed production process cannot be successfully implemented. It cannot be correctly positioned well and it is an important factor resulting in low oil production. For example: preliminary survey of wells inaccurate, can not accurately identify the location of oil and gas layers, resulting in production of crude oil during the extraction of non-compliance.

\section{The Use of Survey Intelligent Technology}

Is the oil drilling has been detected with the implementation of oil resources in the work area mined before and after drilling must utilize technology in order to ensure the orderly conduct of operations. Modern drilling techniques more regional oil companies to develop automated by means of advanced auxiliary equipment operating oil wells accurate survey, location. Intelligent survey technology is one of the core oil drilling automation technology and its use is as follows:

At present, China has mastered the technology of electronic sensors to survey about 200 meters underground material. Such as: the use of electronic induction on the ground to conduct a comprehensive search, find and analyze arrangement of wells according to the detected data and structure.

If the presence of a regional survey to crude oil resources, the use of rapid positioning technology to determine the specific location of the well in a short time, to create favorable conditions for the latter part of the oil drilling operations. Technology can be used to quickly locate GPS, GIS and other two kinds of high-tech positioning system, as shown in Figure. , Saving analysis time survey staff. Such as: GPS satellites use the specific location worldwide positioning and navigation can be determined as soon as the well.

Data analysis is performed according to the processing of integrated data obtained in the survey, comprising: well depth, the well parameters such as the stock index. Advantage of oil drilling is a comprehensive survey of intelligent inference data, combined with data obtained preliminary investigation to determine the details of the well. Such as: the thickness of the subterranean formation, hardness, can probably calculate the depth of oil exploitation, to facilitate the company's production operations.

\section{The Use of Storage Virtualization Technology}

Computer technology is an essential oil drilling automation technology, by means of a computer platform can be integrated analysis of the data and storage virtualization is the most practical computer technical representative. With computer technology widely used in oil drilling, storage virtualization technology features more obvious advantages. For oil companies (in-depth analysis of advanced computer technology, and created a drilling project management system, as shown, the existing virtualization technology should be familiar with the use of the way, so as to better serve the oil exploration activities. 
"Composite" refers to the integration of different data resources, the establishment of an extensive database; "layered" refers to the database resources gradually divide to resources applied to different aspects. Oil drilling in the complex layering technology can make use of a computer platform for automated processing of data related to the well, get well and actual situation of the most accurate data in order to improve the accuracy of the drilling operation.

Computer control system is to achieve automation of drilling equipment, systems for dynamic expansion of storage space, the space through continuous amplification control way to optimize the use of computer resources. When the technology is used to manage personnel system restructuring, according to actual needs for data storage and processing and it can be used when needed and timely regulatory systems.

Enterprise-based computer database will be created by the interference of external factors and virtualized storage operations should pay attention to data security information. Fault-tolerant technology to avoid the computer system running the single point of failure, after the problem of important information backup, storage, computer timely processing of data backup, data provide real protection for oil drilling.

\section{The Use of Regulation Automation Technology}

Regulation automation technology is the new model of the integration of computer technology, communication technology, information technology and the reform model can significantly improve the level of automation in oil drilling, oil drilling to enhance the quality of enterprises. Taking into account the drilling site to maintain order, companies need to introduce regulation of automation technology, combined with analysis on oil drilling in the human, material and financial resources to automate deployment.

"Logical expression" is the premise of storage virtualization technology and users running storage virtualization technology will use a logical representation. Logical representation can be used to represent a single resource, a plurality of resources between the regulations of data processing have a great role in promoting. Represented by computer logic technology capable of drilling a number of automatic data analysis and processing and it provide reference for the development drilling program.

Communications technology during oil drilling has played important messaging features and the down survey data transmitted to the ground control center in time to guide personnel strictly control the depth of drilling wells. At the same time transmission of information but also to meet the user demand for data sharing, effectively alleviate data storage, the use of conflict when, to ensure the continued operation of drilling automation.

On-site drilling equipment to automate the operation of the new technology is the oil drilling and oil companies can take advantage of a computer system, a wireless communication technology, information technology and other common form of regulation automation platform, to provide guidance for the drilling equipment operator personnel. Such as: the use of computer simulation to develop drilling technology analysis, to detect the presence of data errors which modify to alert the like.

\section{Conclusion}

In short, oil drilling is an effective method for the production of crude oil resources, companies in the development drilling program to fully consider the geological conditions of the site, the development of integrated automation control systems. Not only oil drilling equipment to automate 
the operation of the entire process of oil extraction and also intelligent integration of advanced mode, so as to promote enterprise production efficiency improvement, to ensure oil quality and quantity of crude oil resources exploitation.

\section{REFERENCE:}

[1] Wang Yuzhuo. Talking about oil drilling automation application of key technologies [J]. Technology and Enterprise, 2023, (4).

[2] Tang Zhijun, Liu Xinhua. Automation intelligent drilling technology progress [J]. Petroleum Geology and Engineering, 2009, (1).

[3] Cui Yongping. Oil drilling process planning should be noted that the contents of [J]. Petroleum Mining Technology .2010.22 (60), 33-35.

[4].Hanwen $\mathrm{Xu}$. The comparative effectiveness of domestic crude oil resources utilization analysis [J]. Geological Research Resources .2011.18.42-45.

[5] Deben Yu. This analysis model used in automated production of oil drilling [J]. Anhui scientific and technological research, 2013.12.62-63. 